
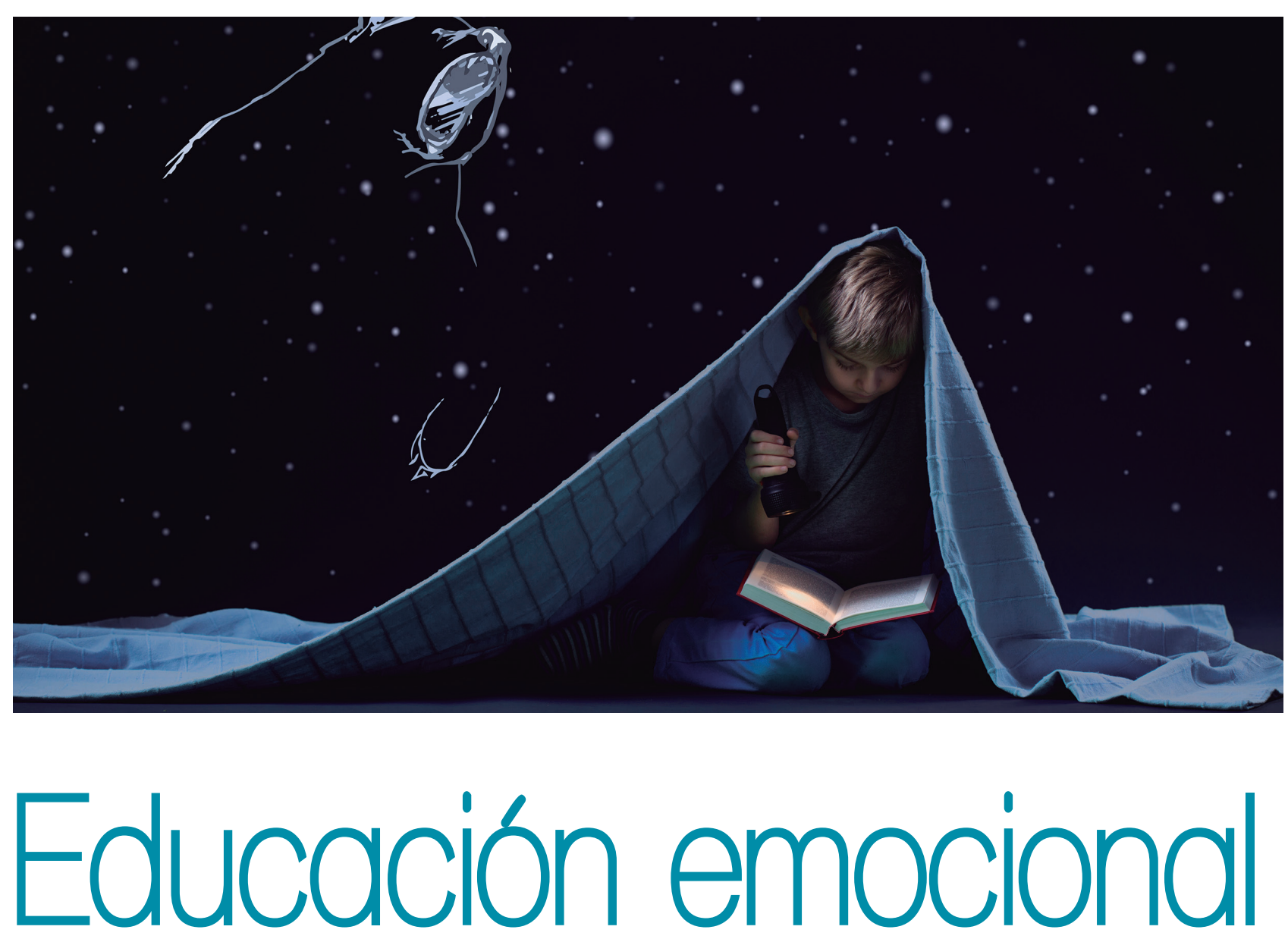

\title{
El cuento como herramienta para su desarrollo
}

En la actualidad podemos encontrar en nuestra sociedad un analfabetismo emocional que es la causa de muchos de los problemas a los que se enfrenta la población. En las aulas es necesario trabajar no sólo la dimensión cognitiva, sino también la emocional. Para ello proponemos el María Martínez-Hita cuento como herramienta para el desarrollo y adquisición de las requeridas competencias emocionales. 


\section{Introducción}

En la actualidad podemos encontrar en nuestra sociedad un analfabetismo emocional que es la causa de muchos de los problemas a los que se enfrenta la población: ansiedad, depresión, problemas de disciplina, violencia, drogadicción, trastornos de la alimentación, etc.

Nos encontramos con que las nuevas generaciones parecen ser más inteligentes y tener mayores capacidades, pero en lo que respecta a las habilidades sociales y emocionales, éstas están decreciendo a un ritmo vertiginoso.

Además, las competencias emocionales tienen hoy en día una gran importancia en el ámbito profesional como indican diversos estudios (Goleman, Boyatzis, y McKee, 2002; Donaldsofellder y Bond, 2004; Albericl y Serrerl, 2005; Hughes, 2005; NAVIO, 2005; y GIARDINI, y FrESE, 2006, citados en BisquerRa y Pérez, 2007).

Por tanto, es de gran importancia una respuesta educativa a toda esta serie de necesidades que encontramos en la sociedad actual. Es necesario reforzar la dimensión emocional, junto con la cognitiva, en el proceso de aprendizaje. Esta preocupación por lo emocional en el ámbito educativo no es novedoso, pero desde la creación de los sistemas educativos modernos en Europa, la educación tradicional ha situado el conocimiento por encima de las emociones.

\section{La inteligencia emocional y la competencia emocional}

La creación del término de inteligencia emocional se le atribuye a Salovey y Mayer, sin embargo, fue Goleman quien difundió y popularizó este concepto con su obra Inteligencia emocional (1995).

\section{Mayer y Salovey afirmaban que:}

[...] inteligencia emocional relaciona la habilidad para percibir con precisión, valorar y expresar emociones, relaciona también la habilidad para acceder y/o generar sentimientos cuando facilitan el pensamiento, también la habilidad para entender emoción y conocimiento emocional y la habilidad para regular emociones que promuevan el crecimiento emocional e intelectual.

(1997, p. 10, citado en DUEÑAs, 2002)

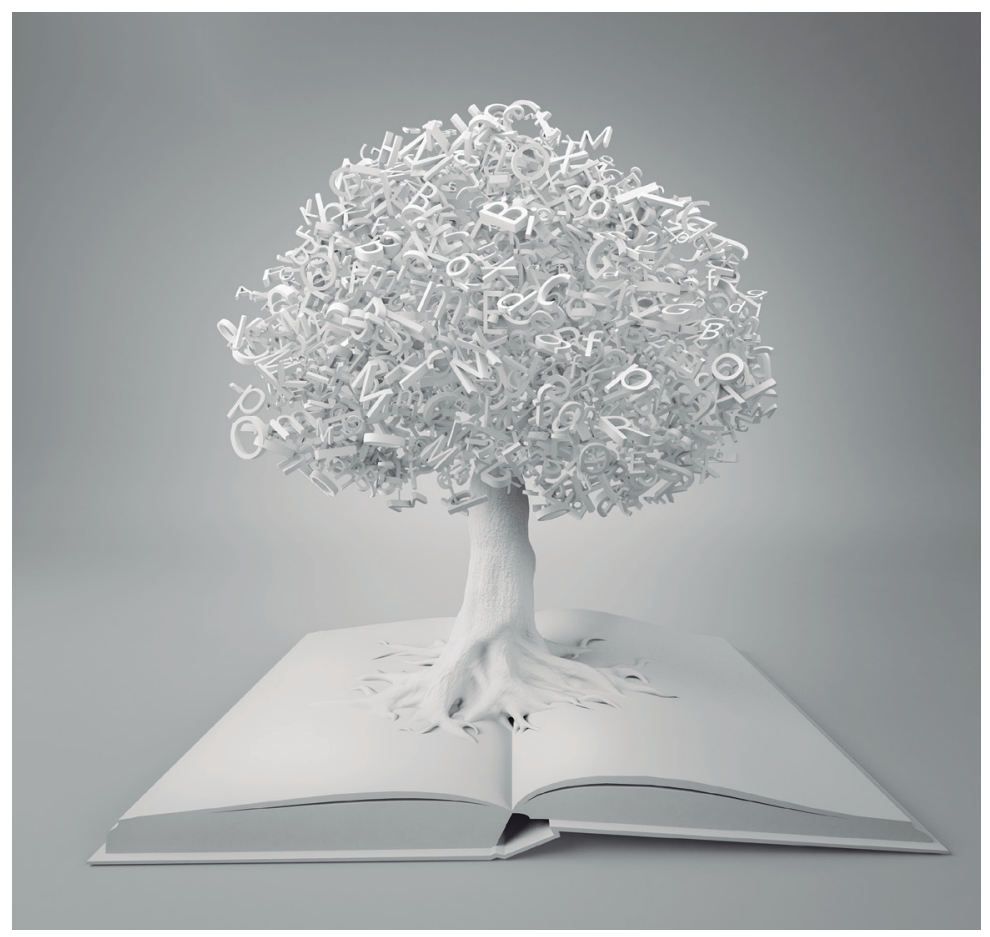

Goleman definió la inteligencia emocional como "capacidad para reconocer nuestros propios sentimientos y los de los demás, para motivarse y gestionar la emocionalidad en nosotros mismos y en las relaciones interpersonales" (Goleman, 1998).

En cuanto a la competencia emocional, debemos señalar en primer lugar que el término competencia hacía referencia a la integración de un saber, un saber hacer y un saber ser. Según Bisquerra y Pérez las competencias emocionales son "un conjunto de conocimientos, capacidades, habilidades y actitudes necesarias para realizar actividades diversas con un cierto nivel de calidad y eficacia" (BISQUeRRA y Pérez, 2007, p. 61).

Siguiendo los planteamientos de las inteligencias múltiples de GARDNER (1993), podemos identificar dos bloques dentro de la competencia emocional:

入 Capacidades de auto-reflexión (inteligencia intrapersonal): identificar las propias emociones y regularlas de forma apropiada.

入 Habilidad de reconocer lo que los demás están pensando y sintiendo (inteligencia interpersonal): habilidades sociales, empatía, asertividad, comunicación no verbal, entre otras.

Tras definir estos dos conceptos, inteligencia y competencia emocional, cabe 

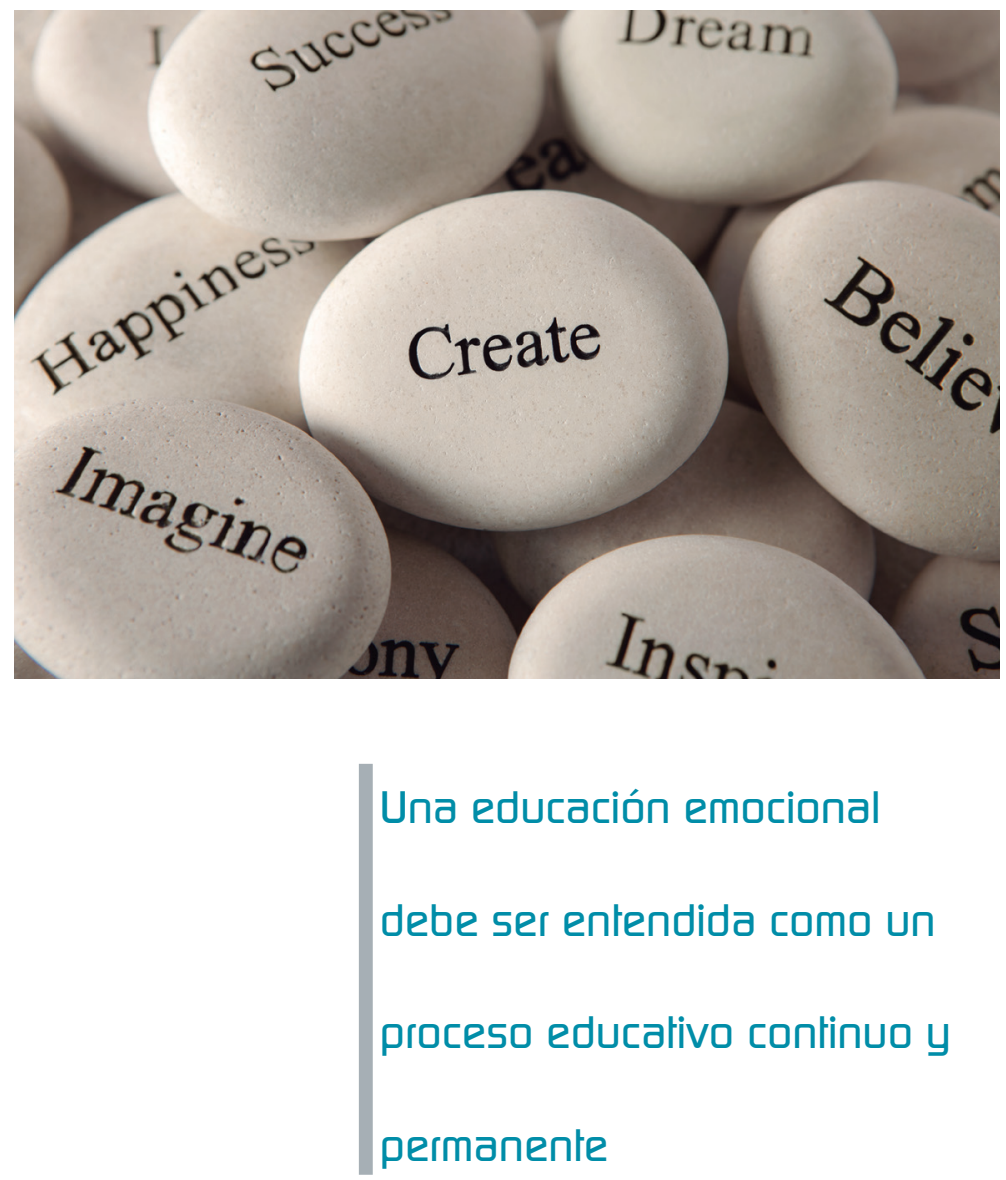

señalar que el primero de ellos es, como indican BISQUeRRA y PÉREZ (2007), un constructo hipotético del campo de la psicología. Sin embargo, todavía existe un debate en torno a la existencia de la inteligencia emocional. Pero de lo que no hay duda es de la existencia e importancia de las competencias emocionales, así como la necesidad de su adquisición.

\section{La educación emocional}

La educación emocional es un proceso educativo continuo y permanente para lograr un desarrollo emocional que, junto con el desarrollo cognitivo, son los componentes principales para conseguir el desarrollo integral de la personalidad.

Una adecuada educación emocional requiere que sean desarrolladas y fomentadas todas las competencias emocionales. Estas competencias deben ser trabajadas desde la infancia, de una forma continua y permanente, para que las personas puedan adquirir un conocimiento tanto sobre sus emociones como las de los demás.

La escuela es uno de los principales espacios educativos donde llevar a cabo esta educación emocional ya que el perio- do escolar es fundamental en la vida del ser humano, puesto que gran parte de nuestras actitudes y hábitos se adquieren en la infancia.

En el marco de la escuela, la educación basada en emociones tiene como objetivo esencial desarrollar las competencias emocionales y sociales en el alumnado, principalmente persigue la adquisición de conocimientos fundamentales sobre las emociones y de cierto grado de competencia en su regulación por parte del alumnado.

Los beneficios de una educación emocional en el aula son inmensos, entre ellos podemos destacar los siguientes (FERNÁNDEZ-BERROCAL y EXTREMERA, 2002; VALLÉS y Vallés, 2003; Palomera, 2008; Acosta Mesas, 2008; Bisquerra, 2008, citados en SÁNCHEZ, 2010):

7 Aumenta la motivación del alumnado.

^ Genera un clima idóneo para el aprendizaje, tanto en el aula como en el centro escolar.

7 Mejora las relaciones inter e intrapersonales.

त Favorece la gestión de los conflictos y la convivencia escolar.

7 Fortalece la confianza.

入 Impulsa el aprendizaje colaborativo y la participación.

$\boldsymbol{\lambda}$ Desarrolla la responsabilidad social en el alumnado.

Por tanto, el aula es uno de los principales espacios donde llevar a cabo una educación emocional, la cual tiene unas consecuencias muy positivas para el proceso de enseñanza-aprendizaje. Sin embargo, no podemos obviar el importante papel e influencia que ejerce la familia y el grupo de iguales en estos aprendizajes.

\section{La educación emocional en el currículo}

En las distintas leyes educativas que han existido y existen en España encontramos referencias sobre la necesidad de una educación emocional en el alumnado, sin embargo, pocas de ellas son de forma explícita.

La actual ley educativa, Ley para la Mejora de la Calidad Educativa (2013), afirma 
que la educación no persigue únicamente desarrollar las habilidades cognitivas, sino que es necesario trabajar otras competencias transversales, entre las que podríamos incluir las emocionales.

Asimismo, establece que "las administraciones educativas dispondrán los medios necesarios para que todo el alumnado alcance el máximo desarrollo personal, intelectual, social y emocional" (LOMCE, 2013, p. 97895).

Sin embargo, a pesar de la presencia de la educación emocional en el currículo, ésta no suele estar presente en la realidad del aula. Muchos docentes y profesionales de la educación sienten que no tienen la suficiente formación para poder llevar a cabo esta enseñanza relativa a las emociones y desconocen cómo realizarla. Por ello, en el siguiente apartado proponemos una manera sencilla, y cada vez más utilizada por un número mayor de docentes, para poner en práctica la requerida educación emocional en la escuela.

\section{El cuento para una educación emocional}

La educación emocional tiene como objetivo principal el desarrollo de las competencias emocionales. Podemos especificar este objetivo en las siguientes finalidades que el alumnado debe alcanzar con nuestra labor docente (DUEÑAS, 2002):

خ Conseguir una vida emocional positiva para llegar a una edad adulta serena y fructífera.

त Controlar los impulsos y las emociones negativas.

7 Ser capaz de expresar y gestionar sus emociones.

7 Desarrollar las habilidades sociales e interpersonales en el marco de un desarrollo afectivo y equilibrado.

7 Desarrollar la capacidad de automotivarse para conseguir una vida personal productiva, y en definitiva, para autorrealizarse.

7 Ser capaz de dar un enfoque correcto a los problemas y tomar las decisiones correctas.
El educador debe seleccionar un cuento que permita el trabajo de las emociones. Con la ayuda de las imágenes, contará dicho cuento poniendo énfasis en aquellas situaciones que provoquen emociones de una manera clara. Viviendo las emociones que transmiten los demás se facilitará el descubrimiento de las emociones propias. Una vez acabado el cuento se debe reflexionar sobre lo que nos ha hecho vivir el relato. Para ello, el docente realizará una serie de preguntas al alumnado, como por ejemplo las siguientes:

У Nombra situaciones en las que, según tu opinión, el personaje del cuento sintió... (el docente dice una determinada emoción: alegría, tristeza, ira, etc.)

У ¿Cómo te sentirías tú ante esa misma situación?

У ¿Recuerdas haber sentido tú esa misma emoción? ¿Cuándo?

У ¿Son tus emociones iguales o parecidas a las de los demás ante una misma situación?

De esta forma, el alumnado será consciente de que, al igual que ellos, las demás personas también sienten distintas emociones y pueden existir situaciones en las que unos experimentan una emoción y otros, otra. Por tanto, se conseguirá la deseada alfabetización emocional que permite el reconocimiento de las emociones en uno mismo y en los demás.

En este artículo proponemos el uso de un cuento como herramienta para desarrollar las competencias emocionales de los estudiantes. Los cuentos no son tan sólo un medio para entretenerse, también reflejan muchos de los acontecimientos que tienen lugar en el mundo interior de los niños. Por ello, los cuentos pueden ayudar a estos niños a afrontar los conflictos internos que aparecen durante su desarrollo y crecimiento.

Asimismo, Hernández Pallares explica en Herranz (2005) que los cuentos son útiles para todos aquéllos que quieren conocerse y aprender las claves que la humanidad ha dejado para solucionar temas tan vitales como el poder, las pérdidas, la envidia, la muerte, la enfermedad, las relaciones padres-hijos, las relaciones fraternas, la identidad sexual, el miedo, los complejos, entre otros.

La lectura de literatura durante la infancia permite al niño explorar mundos de ficción en los que se presentan distintas realidades, en las que se pueden identificar diversas emociones y trabajar dichas emociones a través de personajes de ficción. Por tanto, la lectura de literatura infantil puede contribuir al desarrollo emocional y social de los niños. Para ello podemos utilizar un proceso denomina- 
do "lectura mediada" (RIquelme y Munita, 2011) en el que el educador actuará como mediador entre las emociones de los personajes de la narración y las experiencias vividas por los niños. Un ejemplo de cómo llevar a cabo este proceso con los niños se recoge en el apartado Actividades de aula aunque también puede ser realizado perfectamente por los padres y madres con sus hijos.

\section{Conclusión}

Es un hecho evidente que, en la actualidad, aprender en la escuela sigue basándose en un aprendizaje mental en el que las emociones no tienen ninguna importancia. Sin embargo, nos encontramos con una sociedad y, por tanto, un alumnado, con un significativo déficit emocional y social. Por ello, los docentes no pueden limitarse a transmitir unos conocimientos al alumnado, sino que deben contribuir al desarrollo integral de la personalidad, trabajando por consiguiente la dimensión emocional en el aula.

Existen evidencias sobre los beneficios de estas competencias emocionales, las cuales contribuyen a que los conocimientos académicos se aprendan mejor ya que permiten al alumnado aumentar su motivación o controlar sus impulsos, entre otros aspectos.

La importancia de la adquisición de unas competencias emocionales por parte del alumnado no está relacionada

\section{(ద.) DARA SABER MÂS}

Bisquerra, R., y Pérez, N. (2007). Las competencias emocionales. Educación XXI, 10, 61-82.

DuEÑAS, M. L. (2002). Importancia de la inteligencia emocional: un nuevo reto para la orientación educativa. Educación XXI, 5, 77-96.

RIQUeLME, E. y MUNITA, F. (2011). La lectura mediada de literatura infantil como herramienta para la alfabetización emocional. Estudios Pedagógicos 37(1), 269-277.

Herranz, I. (2005). Cuentoterapia: El poder sanador de los cuentos. Más allá, 34-37.

SÁncheZ, J. (2010). La competencia emocional en la escuela: una propuesta de organización dimensional y criterial. ENSAYOS, Revista de la Facultad de Educación de Albacete, 25, 79-96. únicamente con la formación académica, sino que también se exige desde el ámbito laboral y, además, permitirá que tengan una vida plena, feliz y exitosa en todas sus dimensiones, es decir, laboral, personal y social.

En este sentido abogamos por una educación emocional que debe ser entendida como un proceso educativo, continuo y permanente. La formación de estas capacidades emocionales debe formar parte del currículo, integrándose con las competencias emocionales. Debe existir una sinergia de los contenidos académicos y los emocionales para conseguir el desarrollo de una educación emocional que permita el desarrollo integral de la persona.

Recae en los docentes la responsabilidad de renovar y actualizar los programas y fomentar la educación emocional, que es lo que en la actualidad parecen necesitar los discentes, sin menospreciar los contenidos fundamentales de su formación académica. Para ello, podemos utilizar el cuento como recurso para la educación emocional como hemos sugerido en el presente artículo.

Sin embargo, debemos tener presente que otro espacio educativo muy importante para el desarrollo emocional es la familia. Por ello, se hace necesaria la colaboración de las familias con la escuela desde la edad infantil puesto que son estas dos entidades, la familia y la escuela, las que conforman los principales contextos para el desarrollo emocional de la persona •

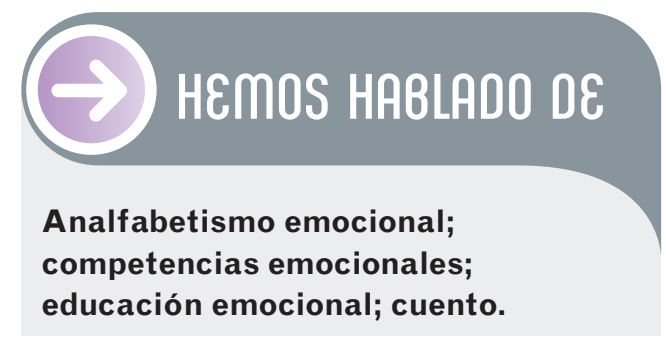

Este artículo fue solicitado por PADRES Y MAESTROS en diciembre de 2016, revisado y aceptado en marzo de 2017. 